\title{
Nutritional quality of Ready-to-Use Therapeutic Foods: focus on lipid composition and vitamin content
}

\author{
Célia Moustiés ${ }^{1}$, Claire Bourlieu-Lacanal ${ }^{2}$ (D), Youna M. Hemery ${ }^{1,3}{ }^{\mathbb{D}}$, Bruno Baréa ${ }^{1}$, \\ Pierre Villeneuve ${ }^{1}$ (D), Adrien Servent ${ }^{1}$ (D), Pascaline Alter ${ }^{1}$, Marc Lebrun ${ }^{1}$, Arnaud Laillou ${ }^{4}$, \\ Frank T. Wieringa ${ }^{1,3}$ (D) and Sylvie Avallone ${ }^{1, *}$ \\ ${ }^{1}$ Qualisud, Univ Montpellier, Avignon Université, CIRAD, Institut Agro, IRD, Université de La Réunion, Montpellier, France \\ 2 IATE, Univ Montpellier, INRAE, Institut Agro, Montpellier, France \\ ${ }^{3}$ UMR QualiSud, Institut de Recherche pour le Développement (IRD), Montpellier, France \\ ${ }^{4}$ UNICEF Ethiopia, Addis Ababa, Ethiopia
}

Received 3 August 2021 - Accepted 8 February 2022

\begin{abstract}
Severe Acute Malnutrition (SAM) is still a public health issue in many low-income and middleincome countries. Its management has changed with the development of Ready-to-Use Therapeutic Foods (RUTF) that are energy-dense, lipid-based, micronutrient-enriched foods. The purpose of the present study was to define some aspects of the nutritional profile (in particular, lipid content, fatty acids profile, lipophilic vitamin content), oxidative status, and mycotoxin content of three RUTF products (of which two manufactured in Asia and one in Europe), at different time points during their storage. All RUTF displayed good lipid stability, with peroxide values $<10 \mathrm{meqO}_{2} / \mathrm{kg}$ lipids, acidity index $<0.6 \mathrm{~g} / 100 \mathrm{~g}$ lipids, and very low amounts of secondary oxidation volatile compounds. Only the one produced in Europe complied with the international recommendations on vitamin A and E contents. Lipid content ranged from $28.7 \pm 0.5$ to $41.2 \pm 2.4 \mathrm{~g} / 100 \mathrm{~g}$. Oleic acid, palmitic acid, and linoleic acid $(47.2 \pm 7.4 \%, 26.8 \pm 2.1 \%$, and $12.4 \pm 3.9 \%$ of total lipids, respectively) were the main fatty acids. Only one of the samples made in Asia exceeded the regulatory limit of mycotoxins. The RUTF lipid phase was rather stable at ambient temperature from 9 to 12 months, and appropriate packaging may have contributed to a major stability.
\end{abstract}

Keywords: fortified food / infant nutrition / lipid oxidation / secondary oxidation volatile compounds / lipophilic vitamins / vitamin A

\begin{abstract}
Résumé - Qualité nutritionnelle des aliments thérapeutiques prêts à l'emploi : composition lipidique et les teneurs en vitamines. La malnutrition aiguë sévère (MAS) reste un problème de santé publique dans de nombreux pays à revenu faible ou intermédiaire. Sa prise en charge a changé avec le développement des aliments thérapeutiques prêts à l'emploi (ATPE) qui sont des aliments denses en énergie, à base de lipides et enrichis en micronutriments. L'objectif de la présente étude était de définir certains aspects du profil nutritionnel (en particulier, la teneur en lipides, le profil des acides gras, la teneur en vitamines lipophiles), le statut oxydatif et la teneur en mycotoxines de trois produits RUTF (dont deux fabriqués en Asie et un en Europe), et ce à différents moments de leur stockage. Tous les RUTF présentaient une bonne stabilité lipidique, avec des indices de peroxyde $<10 \mathrm{meqO}_{2} / \mathrm{kg}$ de lipides, un indice d'acidité $<0,6 \mathrm{~g} / 100 \mathrm{~g}$ de lipides, et de très faibles quantités de composés volatils d'oxydation secondaire. Seul celui produit en Europe était conforme aux recommandations internationales sur les teneurs en vitamines A et E. La teneur en lipides variait de 28,7 $\pm 0,5$ à 41,2 $\pm 2,4 \mathrm{~g} / 100 \mathrm{~g}$. Les principaux acides gras étaient l'acide oléique, l'acide palmitique et l'acide linoléique $(47,2 \pm 7,4 \%, 26,8 \pm 2,1 \%$ et $12,4 \pm 3,9 \%$ des lipides totaux, respectivement). Un seul des échantillons fabriqués en Asie dépassait la limite réglementaire des teneurs en mycotoxines. La phase lipidique des RUTF était plutôt stable à température ambiante de 9 à 12 mois, et un conditionnement approprié a pu contribuer à cette bonne stabilité.
\end{abstract}

Mots clés : aliments enrichis / nutrition infantile / oxydation des lipides / composés volatils d'oxydation secondaire / vitamines lipophiles / vitamine A

\footnotetext{
*Correspondence: sylvie. avallone@supagro.fr
} 


\section{Introduction}

Severe Acute Malnutrition (SAM), or wasting, occurs when nutrient intake is insufficient. This imbalance can arise because of a reduced nutrient intake, for instance in situations of food insecurity, or because of increased physiological requirements, for instance in pregnancy or disease. More often, SAM is explained by a combination of these two conditions. Conflicts, climate-related events, and the current COVID-19 pandemic undermine food security and consequently the nutritional status, increasing the rate of wasting (FAO et al., 2018; Headey et al., 2020).

Infants and children aged 6-59 months are considered to suffer from SAM if they have a mid-upper arm circumference (MUAC) $<115 \mathrm{~mm}$, or a weight-for-height $<-3 \mathrm{Z}$-score of the WHO growth standards, or have bilateral oedema (WHO, 2013). Globally, more than 50 million of children suffer from SAM that is a major cause of mortality in under-5-years-old children. Therefore, prevention and management of SAM are critical for child survival (Development Initiatives, 2018). To treat SAM in children, Ready-to-Use Therapeutic Food (RUTF) was developed in the 1990s and applied in the early years of 2000s (Santini et al., 2013). The first formula was based on peanut paste and adapted from therapeutic milk F-100, in accordance with the United Nations guidelines for the care and management of SAM (Briend, 2001; Diop et al., 2003; Manary, 2006; WHO et al., 2007). Today, RUTFs are a key element of the community-based management of SAM because they are easy to handle, do not require any home preparation, and increase the time available for family care (Diop et al., 2003; Kapil, 2009). The low water activity limits bacterial growth (Briend, 2001), and RUTFs can be safely stored in ambient tropical conditions if well packaged because they do not require cold storage (WHO et al., 2007).

The reference RUTF formulation is an oleaginous paste that contains sugar, milk powder, vegetable oils, and added vitamins and minerals. The reference RUTF formulation is an oleaginous paste that contains sugar, milk powder, vegetable oils, and added vitamins and minerals. All ingredients are micronized (so that the particle size does not exceed $200 \mu \mathrm{m}$ ) to allow a good homogenization and paste texture after mixing (Manary, 2006). RUTF stability depends on the food matrix particle size, lipid amount, and oxidative status of the ingredients as well as their interactions (Mc Clements, 2000). RUTF stability also depends on the ambient humidity and presence of oxygen (Briend, 2001).

RUTF acceptability is influenced by the local dietary patterns and preferences. Therefore, various RUTF types have been developed in different countries, and their sensory properties have been adapted to the preferences, culture and food habits of the local populations. For instance, RUTF made from rice, lentil and chickpeas, or with a cumin flavor, have been developed in Bangladesh; from mung beans, soybeans, rice and sesame in Vietnam; and from roasted peanuts in India (Mridha et al., 2012; Nga et al., 2013; Wieringa et al., 2013; Thapa et al., 2017; Sigh et al., 2018; Choudhury et al., 2018). The peanut taste and paste texture are better accepted in Africa than in Asia. During the last decade, RUTF formulations and costs have been optimized by linear programming, taking into account local resources (Dibari et al., 2012; Owino et al., 2014; Weber and Callaghan, 2016).
RUTFs are generally characterized by a biphasic system (solid/oil emulsion) made of water-soluble components dispersed in a hydrophobic phase (Santini et al., 2013). More generally, RUTF's fatty acid profile, mineral and vitamin contents are designed to cover the nutritional needs of children and make them food matrices of high nutritional density. They have high energy density due to their high lipid content which represents more than $520 \mathrm{kcal} / 100 \mathrm{~g}$, and considering that triacylglycerols bring $9 \mathrm{kcal} / \mathrm{g}$ such lipid density is equivalent to $\sim 58 \mathrm{~g} \mathrm{lipid} / 100 \mathrm{~g}$ of RUTF (Khara et al., 2004; Santini et al., 2013). To reach their nutritional target, RUTFs must contain specific quantities of four lipophilic and nine hydrophilic vitamins that can be added in the form of a micronutrient premix (Manary, 2006; WHO et al., 2007).

Lipids are crucial nutrients for the health of young children: fats are a source of energy and are essential for many biological functions, including growth and development. In fact, they behave as transport vehicle for lipophilic vitamins (Kritchevsky, 2002), and polyunsaturated fatty acids (PUFA), especially $n-3$ ones, are essential for retina development and brain functions (Guesnet and Alessandri, 2011). According to the RUTF composition recommendations (WHO et al., 2007), lipids should cover $45-60 \%$ of the total energy. In accordance with the requirements of the United Nations agencies, $n-6$ and $n-3$ fatty acids should represent $3-10 \%$ and $0.3-2.5 \%$, respectively, of the total energy. Concerning $n-9$ fatty acids, RUTFs are generally characterized by high content in oleic acid and other monounsaturated fatty acids (Manary, 2006). In such emulsions, the PUFA content favors the formation of oxidative degradation products. On the other hand, pastes formulated using specific peanut varieties with higher oleic acid content are less prone to lipid oxidation (Riveros et al., 2010). Moreover, using high oleic peanuts, selected to decrease the $n-6$ content in RUTF, without increasing the $n-3$ content, improves the docosahexaenoic acid (DHA) status in under 5-years-old African children (Hsieh et al., 2016). A lipid-based nutrient supplement, used as food supplement, has been developed with $n-3$ fortification because restoring $n-3$ status also is important in malnourished infants (Gaur et al., 2017); however, the use of high levels of n-3 fatty acids in RUTF has to be discouraged as it has an inhibitory effect on DHA synthesis (Brenna et al., 2015).

Assessing the oxidative stability of $n$-3 PUFA-enriched RUTFs before studying their biological efficacy should be a priority, but data are not available in the literature yet. Lipid oxidation can limit RUTF shelf life, and generates primary and secondary oxidation compounds by a complex radical reaction that includes initiation, propagation, and termination steps. Different pathways can induce the initiation of this reaction, such as enzymatic oxidation, autoxidation, and the presence of singlet oxygen. The primary compounds, mainly hydroperoxides, are generated at the beginning of the propagation step due to external factors, such as oxygen, light or metal catalysts, especially $\mathrm{Fe}^{2+}, \mathrm{Fe}^{3+}$. Then hydroperoxides are cleaved to form secondary oxidation compounds, for instance volatile compounds (Berton-Carabin et al., 2014).

Sometimes, antioxidants (tocopherols, L-ascorbyl palmitate) are added to limit or retard oxidation reactions with the aim of stabilizing the overall quality and nutritional profiles of lipid-rich pastes (Nestel et al., 2003). Moreover, to improve RUTF stability, producers can avoid high temperatures during 
Table 1. Characteristics of the Ready-to-Use Therapeutic Foods (RUTFs) selected for the study.

\begin{tabular}{|c|c|c|c|}
\hline Sample name & Origin & $\begin{array}{l}\text { Storage duration and } \\
\text { shelf life (months) }\end{array}$ & Ingredients \\
\hline RUTF_1 & Cambodia & $\begin{array}{l}* \text { SD: } 6-9 \\
* * \text { SL: } 12\end{array}$ & $\begin{array}{l}\text { Vegetable oil, canola oil, mungo bean, soybean, sugar, } \\
\text { maltodextrin, fish, rice, coconut, premix }\end{array}$ \\
\hline RUTF_2 & France & $\begin{array}{l}* \text { SD: } 3-5-11 \\
* * \text { SL: } 24\end{array}$ & $\begin{array}{l}\text { Sugar, peanuts, vegetable oils (rape, palm, soya), skimmed milk } \\
\text { powder, whey powder, premix***, stabilizer (fully hydrogenated } \\
\text { fat, mono and diglycerides), vegetable lecithin (soya or sunflower) }\end{array}$ \\
\hline
\end{tabular}

${ }^{*} \mathrm{SD}$ : storage duration; ${ }^{* * \mathrm{SL}}$ : shelf life; $* * *$ premix of vitamins and minerals.

processing, and use packaging with good barrier properties against water and gas oxygen. Nitrogen flushing is sometimes used to decrease the oxygen content within the package. In general, RUTF expiry date without airtight packaging is only 3-4 months, while nitrogen flush packaging can extend the expiry date up to 24 months (Manary, 2006).

RUTF producers carried out studies to evaluate the shelf life of their products. However, to the best of our knowledge, no study has been published on RUTF oxidation status, lipid composition, and lipophilic vitamin content at different storage times. Therefore, the aim of the present work was to assess the nutritional quality (lipid profile, fatty acid composition, vitamin $\mathrm{A}$ and $\mathrm{E}$ contents) and the potential degradation (lipid oxidation, mycotoxin content, secondary oxidation volatile compounds) of three RUTF types produced by three companies in different countries (one in Europe and two in Asia), and stored from 9 to 12 months. Although one product represents the majority of RUTFs used worldwide, we chose to include other types of RUTFs in our panel to cover the diversity of products on the market and to study their composition and stability. Indeed, the RUTF sampled have diverse source of lipids and proteins and RUTF 1 and 3 have soft rather than pasty textures.

\section{Materials and methods}

\subsection{Materials and chemicals}

Solvents (ethanol, hexane, diethyl ether, acetic acid, chloroform, methanol, acetone, tert-butyl methyl ether), reagents (potassium hydroxide, phenolphthalein, sodium methylate hydrochloric methanol, potassium iodide, thiodene, sodium thiosulfate, copper sulfate) and High Performance Liquid Chromatography (HPLC) standards ( $\alpha$-tocopherol, $\delta$-tocopherol, $\gamma$-tocopherol, $\beta$-tocopherol, retinol palmitate, retinol acetate) were obtained from Sigma-Aldrich (SaintQuentin-Fallavier, France). Mycotoxin standards (aflatoxins, ochratoxins, fumonisins, trichothecenes, zearalenone, beauvericins) were from R-Biopharm (Rhône Ltd, Glasgow, UK). Polytetrafluoroethylene membranes were purchased from Sartorius (Palaiseau, France).

The following lipid standards for Thin Layer Chromatography (TLC) were purchased from Sigma-Aldrich (SaintQuentin-Fallavier, France): triacylglycerols (TAG: tripalmitin, triolein, trilinolein), diacylglycerols (DAG: dipalmitin, diolein, dilinolein), monoacylglycerols (MAG: monopalmitin, monoolein, monolinolein), and free fatty acids (FFA: palmitic acid, oleic acid, linoleic acid). The HPLC-grade $\mathrm{mQ}$ water used in all the experiments was produced in our lab.

Three RUTF types from three countries (Cambodia, France, Vietnam) were sent by local companies to our laboratory (Montpellier, France) (Tab. 1). These three products were tested rapidly at reception (i.e., after 3,6 , or 11 months of "in field" storage), and then stored in the laboratory at ambient temperature $\left(\sim 20^{\circ} \mathrm{C}\right)$ for further characterization. The number of RUTF products tested was limited to three, but these included the European RUTF that is largely distributed in Africa, and two other RUTF types that are made with local resources and are more representative of the RUTFs locally developed and distributed in Asia. The European RUTF is the RUTF most used in the world, and thus was considered in the present study as the reference. The Cambodian RUTF is adapted to the sensory preferences of local populations, and is based on fish rather than milk ingredients to provide the required protein content. For each product, formulation, packaging and storage time after the production date were noted. The products were labeled as follows: RUTF_X_Y to indicate that the RUTF was produced by brand (X) and had been stored for $(\mathrm{Y})$ months when the analysis started.

To obtain a representative sample, several unit-doses of each product were mixed to reach a total weight of around $200 \mathrm{~g}$. After opening the package, the vitamin profile, dry matter $(D M)$ and water activity $\left(\mathrm{a}_{\mathrm{w}}\right)$ of each product were immediately analyzed. The rest of the samples was aliquoted in different bags and stored at $-80^{\circ} \mathrm{C}$ until analysis (mycotoxins, total and neutral lipids, secondary oxidation volatile compounds). The analyses were always carried out on the same day as the packages were opened.

\subsection{Dry matter and water activity determination}

The DM content and $\mathrm{a}_{\mathrm{w}}$ were determined in triplicate following the method 44-15A (AACC, 2000). DM was obtained by drying $3 \mathrm{~g}$ of each sample at $105^{\circ} \mathrm{C}$ in a Memmert heat chamber (model 100 Schwabach, Germany) until constant weight. Samples and their dehydrated residues were precisely weighted on a Mettler AE166 balance (Viroflay, France). $\mathrm{A}_{\mathrm{w}}$ was determined using approximately $1 \mathrm{~g}$ of each sample and a 4TE AQUALAB water activity meter (Hopkins, USA), at $25^{\circ} \mathrm{C}$. 


\subsection{Peroxide value (PV) determination}

The PVs were determined by iodometric titration using the AOCS method (AOCS, 1996) with slight modifications: approximately $200 \mathrm{mg}$ of oil were dissolved in $1 \mathrm{~mL}$ of chloroform. Then, $1.5 \mathrm{~mL}$ of acetic acid and $0.1 \mathrm{~mL}$ of saturated potassium iodide were added, and the solution was shaken for $1 \mathrm{~min}$ and placed in the dark for $5 \mathrm{~min}$. After addition of $7.5 \mathrm{~mL}$ of distilled water and iodine indicator, the solution was titrated with $0.002 \mathrm{~N} \mathrm{Na}_{2} \mathrm{~S}_{2} \mathrm{O}_{3}$ until the color disappeared. Before the first titration, a blank determination was made, and the PV was calculated using the following equation:

$$
P V=(V s-V b) \times N \times \frac{1000}{W},
$$

where $\mathrm{PV}=\mathrm{mEqO}_{2} / \mathrm{kg}$ of lipid; $\mathrm{Vs}=$ volume of $\mathrm{Na}_{2} \mathrm{~S}_{2} \mathrm{O}_{3}$ used in the sample $(\mathrm{mL}) ; \mathrm{Vb}=$ volume of $\mathrm{Na}_{2} \mathrm{~S}_{2} \mathrm{O}_{3}$ used in the blank sample $(\mathrm{mL}) ; \mathrm{N}=$ normality of $\mathrm{Na}_{2} \mathrm{~S}_{2} \mathrm{O}_{3}(\mathrm{mEq} / \mathrm{mL}) ; \mathrm{W}=$ lipid weight (g).

\subsection{Acid value (AV) determination}

The AVs were determined by titration (AOAC, 1990) with approximatively $200 \mathrm{mg}$ of lipids dissolved in $0.4 \mathrm{~mL}$ ethanol/ diethyl oxide $(50: 50, \mathrm{v} / \mathrm{v})$. Then, phenolphthalein was added, and the solution was titrated with $0.01 \mathrm{~N} \mathrm{KOH}$ until the pink color persisted for at least $10 \mathrm{~s}$. Before the first titration, a blank determination was made, and the AV was expressed in oleic acid equivalents and calculated using the following equation:

$$
A V=(V s-V b) \times N \times \frac{282.46}{(10 \times W)},
$$

where $\mathrm{AV}=\%$ lipid; $\mathrm{Vs}=\mathrm{KOH}$ volume used for sample titration $(\mathrm{mL}) ; \mathrm{Vb}=\mathrm{KOH}$ volume used for blank titration $(\mathrm{mL}) ; \mathrm{N}=$ normality of $\mathrm{KOH} ; 282.46=$ molecular weight of oleic acid $(\mathrm{g} / \mathrm{mol}) ; \mathrm{W}=$ lipid weight $(\mathrm{g})$.

\subsection{Secondary oxidation volatile compound determination}

Secondary oxidation volatile compounds were extracted using headspace solid-phase microextraction gas chromatography (Lebrun et al., 2008). Each sample was analyzed in triplicate. Samples $(1 \mathrm{~g})$ were placed in headspace vials $(10 \mathrm{~mL})$ with benzyl butyrate $(5 \mu \mathrm{L} / 100 \mathrm{~mL})$ as internal standard for semi-quantification.

Extraction and analysis were carried out on divinylbenzene/carboxen/polydimethylsiloxane fibers (Supelco, Bellefonte, Pennsylvania, USA), and a tandem gas chromatograph 6890/MSD 5973 system (Agilent Technologies, Palo Alto, USA) with a Gerstel Multipurpose Sampler MPS-2, following the method developed by Moustiés et al. (2019).

Data were analyzed with MassHunter version B. 06.00 (Agilent Technologies, Palo Alto, USA). Peaks were identified by comparing the obtained mass spectra with those of the NIST 14 database. Co-injection of series of alkanes, from $\mathrm{C}_{8}$ to $\mathrm{C}_{20}$
(Sigma-Aldrich), was used for the calculation of Kovats retention indices that were then compared with those found in the literature (Flavornet and the Pherobase websites and NIST).

\subsection{Vitamin A and E measurement}

Typically, one gram of RUTF was mixed with $20 \mathrm{~mL}$ of distilled water and gently shaken for $10 \mathrm{~min}$, and analyses were carried out using the method previously described by Moustiés et al. (2019). Vitamins were quantified by ultra-performance liquid chromatography using an Agilent System 1260 Series HPLC system (Massy, France) and a polymeric C30 column $(4.6 \mathrm{~mm}$ i.d. $\times 250 \mathrm{~mm}, 5 \mu \mathrm{m}$ particle size, YMC, Inc Wilmington NC). Chromatograms were recorded at $325 \mathrm{~nm}$ for vitamin A. Vitamin E was measured in the same chromatographic conditions using $296 \mathrm{~nm}$ for excitation and $330 \mathrm{~nm}$ for emission. Each sample was analyzed five times.

Vitamin A activity was expressed as retinol equivalents (RE) using the following equivalence: $1 \mu \mathrm{g}$ retinol equivalent $=1.146 \mu \mathrm{g}$ retinol acetate $=1.832 \mu \mathrm{g}$ retinol palmitate .

Vitamin E activity was expressed as $\alpha$-tocopherol equivalents (TE) (Shils and Shike, 2006). The activities of other isomers are: $\alpha$-tocopheryl acetate $=0.7 \mathrm{TE} / \mathrm{mg}$, $\beta$ tocopherol $=0.4 \mathrm{TE} / \mathrm{mg}, \gamma$ tocopherol $=0.2 \mathrm{TE} / \mathrm{mg}$, and for $\delta$ tocopherol $=0.1 \mathrm{TE} / \mathrm{mg}$. Vitamin $\mathrm{E}$ activity can be calculated and expressed in $\alpha$-TE in $\mathrm{mg}$ for $100 \mathrm{~g}$, with the following equation:

$$
\begin{aligned}
\alpha-T E & =(1 \times \alpha-T)+(0.7 \times \alpha-T A) \\
& +(0.4 \times \beta-T)+(0.2 \times \gamma-T) \\
& +(0.1 \times \delta-T),
\end{aligned}
$$

where $\alpha$-TE: alpha tocopherol equivalent; T: tocopherol; TA: tocopherol acetate; $\alpha$ : $\alpha$-tocopherol; $\beta$ : $\beta$-tocopherol; $\gamma: \gamma$-tocopherol; $\delta$ : $\delta$-tocopherol.

\subsection{Lipid content measurement}

Lipid content was determined gravimetrically using the Folch's method (Folch et al., 1957) in triplicate, and each extract was then analyzed in duplicate. Briefly, lipids were extracted from thoroughly homogenized food samples using chloroform/methanol $(2: 1, \mathrm{v} / \mathrm{v})$. Five grams of sample was rehydrated with $10 \% \mathrm{w} / \mathrm{w}$ distilled water during $10 \mathrm{~min}$, and extracted with a sample/solvent ratio of 1:27 (w/v) for $1 \mathrm{~min}$ at $10000 \mathrm{rpm}$ (Ultra-Turrax T8, IKA Labortechnick, Staufen, Germany). $\mathrm{NaCl} 0.73 \%$ (w/v) was then added to the organic phase. After dephasing, the lower phase was filtered and retrieved. Then, chloroform/methanol was added again with an initial sample/solvent ratio of 1:20 (w/v) and the sample was washed again with $\mathrm{NaCl} 0.58 \%(\mathrm{w} / \mathrm{v})$. The lower organic layer was again collected and added to the previous one. The organic layer was then filtered over a paper filter (Whatman paper, grade 1). Solvent was evaporated with a rotavapor at $40^{\circ} \mathrm{C}$ until constant weight and residual lipids were precisely weighted (Laborota 400-efficient, Heidolph, Schawabach, Germany). 


\subsection{Lipid profile determination by thin layer chromatography}

Neutral lipids were separated by one-dimensional migration using hexane/diethylether/acetic acid (65:35:1, v/v/v). For each sample, 4 and $8 \mu \mathrm{L}$ of a lipid solution $(0.5 \mathrm{mg} / \mathrm{mL})$ were applied automatically on the thin layer. The equipment used was a Camag automatic TLC sampler 4 (Muttenz, Switzerland) controlled by the Wincats software system (2008). After migration, plates (HPTLC 60F254, $20 \times 10 \mathrm{~cm}$; Merck, Darmstadt, Germany) were dried at $70{ }^{\circ} \mathrm{C}$ for $2 \mathrm{~min}$, and then lipids revealed with a solution of $15.9 \%$ copper sulfate in orthophosphoric acid/water $(92: 8, \mathrm{v} / \mathrm{v})$. Then, plates were scanned by a laser UV detection system (Camag TLC scanner 3, Muttenz, Switzerland). The wavelength of maximum absorption was $500 \mathrm{~nm}$ and the spots were quantified by integration of the spot intensities with the Wincats software (2008). Calibration was done with TAG, DAG, MAG, and FFA.

\subsection{Mycotoxin analysis}

Five grams of each RUTF sample was homogenized with $20 \mathrm{~mL}$ of acetonitrile/water/acetic acid (50:50:1; v/v/v), and analyzed as described by Moustiés et al. (2019). Briefly, extracts were analyzed by ultra-HPLC (Olagunju et al., 2018) with an injection volume of $20 \mu \mathrm{L}$, an LC 20 AD Shimadzu pump (Kyoto, Japan), an SIL 20 A XR Shimadzu autosampler, and a Kinetex $2.6 \mu \mathrm{m}$ XB-C18 100A column $(50 \mathrm{~mm} \times 2.1 \mathrm{~mm}$, Phenomenex Inc., California, USA). The oven temperature was $50{ }^{\circ} \mathrm{C}$. The mobile phase A was water $/ 0.5 \%$ acetic acid, and the mix $\mathrm{B}$ was isopropanol $/ 0.5 \%$ acetic acid at a flow rate of $0.4 \mathrm{~mL} / \mathrm{min}$.

Standard calibration curves were established with several mycotoxins (aflatoxins, ochratoxins, fumonisins, trichothecenes, zearalenone, beauvericins) (R-Biopharm Rhône Ltd, Glasgow, UK). The contents were expressed in $\mu \mathrm{g} / \mathrm{kg}$ of RUTF and analyses were performed in triplicate.

\subsection{Packaging characterization}

Packaging was characterized by Fourier-transform infrared spectroscopy. Spectra were recorded using a Nexus 5700 spectrometer (Thermo Electron Corp., Massachusetts, USA) equipped with the diamond ATR Smart Orbit Accessory inserted as described by Moustiés et al. (2019). The oxygen and water permeabilities were obtained from the literature for standard polymers (Massey, 2003).

\subsection{Statistical analysis}

All experiments were performed three times for lipid, $\mathrm{a}_{\mathrm{w}}$, water content, secondary oxidation volatile compound and mycotoxin analysis, five times for lipophilic vitamin measurement, and six times for total fatty acid, lipid class, and acid, and peroxide value determination. Analyses of variance (one-way ANOVA) were performed using Statistica 13.3 (TIBCO, California, USA), followed by Tukey post hoc tests, to identify significant differences between samples. Differences were considered significant with $p$ values $<0.05$.

\section{Results}

\subsection{RUTF formulations}

The typical formulations of the three RUTFs are shown in Table 1 . They contained 10 to 14 ingredients, among which vegetable oils and sugar were important because of they allowed reaching the adequate energy density. Two products included milk powder, and one contained dried fish powder instead of milk, to comply with the preferences of Asian consumers and reduce production costs. Both Asian RUTFs contained local ingredients (mungo beans, sesame, rice or soya, coconut). Two RUTFs contained food additives, such as hydrogenated fat or lecithin, to preserve their nutritional profiles or to enhance their sensorial properties (taste or texture).

\section{$3.2 a_{w}$ and water content}

All RUTFs complied with the recommendations in term of $\mathrm{a}_{\mathrm{w}}$ (i.e., < 0.6) (FAO/WHO, 2016; FAO/WHO, 2019). Indeed, the $\mathrm{a}_{\mathrm{w}}$ values ranged from $0.23 \pm 0.01$ to $0.40 \pm 0.00$ (Tab. 2), and increased during storage $(p<0.05)$. The water content ranged from $2.29 \pm 0.28 \%$ to $3.79 \pm 0.10 \%$, and was not affected by the time of storage, except for RUTF_2 that displayed a significant increase in water content at month 11 of storage (Tab. 2). Two products had water contents above the recommendations (i.e., $>2.5 \%$ ) (FAO/WHO, 2016).

\subsection{Peroxide and acid values}

All RUTFs complied with the international regulations concerning PVs (i.e., $<10 \mathrm{meqO}_{2}$ per $\mathrm{kg}$ of lipids) and $\mathrm{AVs}$ (i.e., 0.6\% of lipids) (CXS19-1981, FAO/WHO, 2019) (Fig. 1). No significant change in oxidation marker values was observed for the samples analyzed at different time points during storage, except for RUTF_1 that displayed a decrease in AV over time $(p>0.05)$.

\subsection{Secondary oxidation volatile compound determination}

The main secondary oxidation volatile compounds identified in RUTFs were hexanal, pentanal and nonanal (Tab. 2). The predominant secondary oxidation volatile compound was hexanal the concentration of which ranged from $2.11 \mathrm{e}^{-10} \pm 1.97 \mathrm{e}^{-10}$ to $1.11 \mathrm{e}^{-08} \pm 3.22 \mathrm{e}^{-09} \mathrm{mg}$ eq benzyl butyrate $/ 100 \mathrm{~g}$. The three volatile compounds tend to increase with the storage time of the RUTFs. However, it is not possible to say whether these trends are significant or not between storage times because the method used to estimate them is only semi-quantitative. A homogeneity test was carried out on the data and this confirmed that there are variations between the different samples. Hexanal, pentanal and nonanal are known to be produced when linoleic acid and oleic acid are cleaved.

\subsection{Vitamin E and A content}

Two products (RUTF_1 and RUTF_2) met the recommendations for vitamin $\mathrm{E}$ content (i.e., $>20 \mathrm{mg} / 100 \mathrm{~g}$ ) 


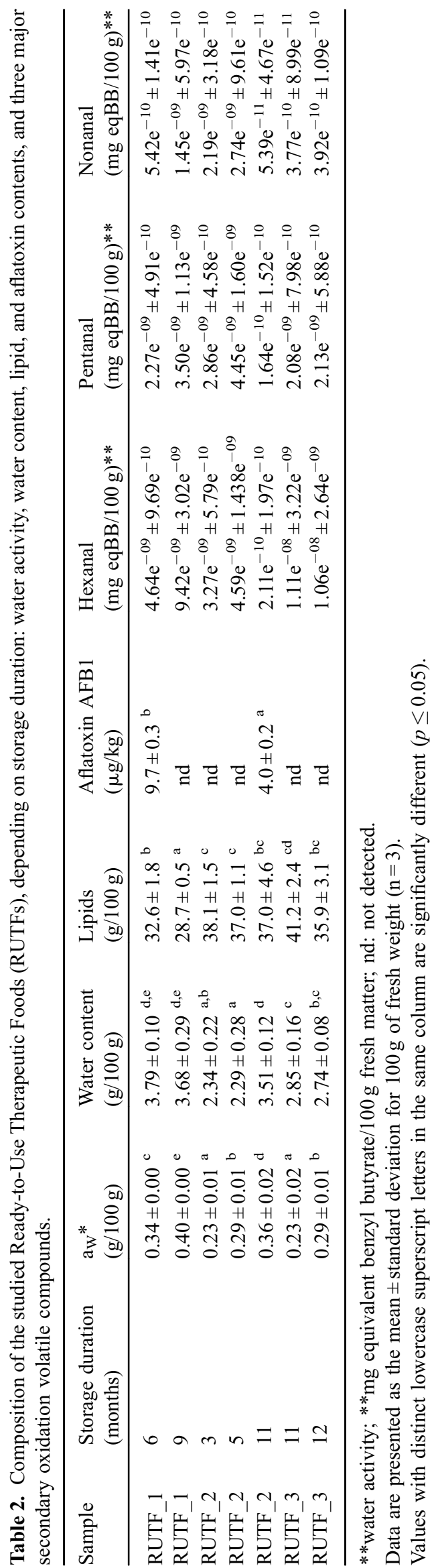



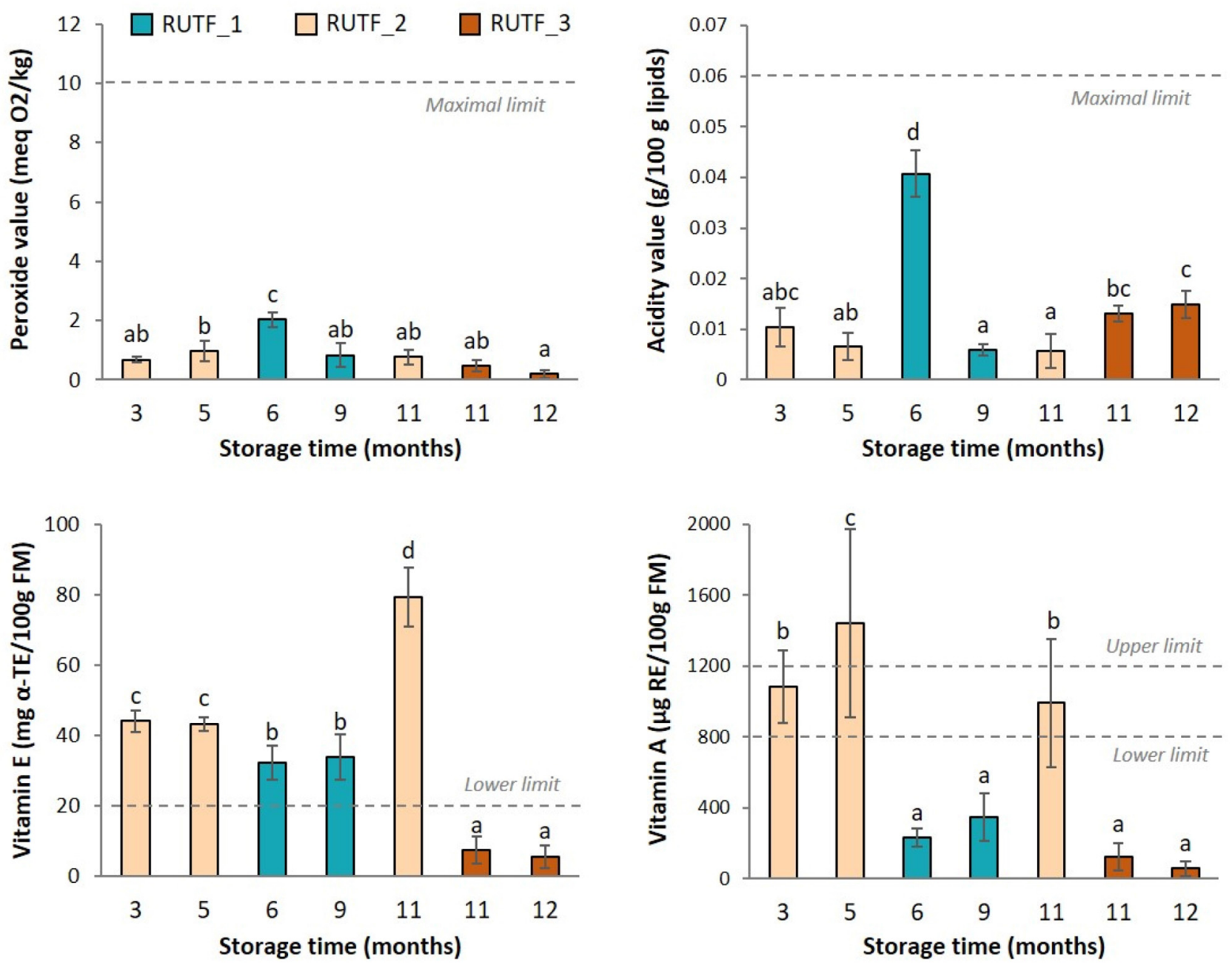

Fig. 1. Peroxide value, acid value and vitamins $A$ and $E$ contents of the studied Ready-to-Use Therapeutic Foods (RUTFs). The products are classified according to the increasing time of storage, from left to right.

Maximum acceptable peroxide value: $10 \mathrm{mEqO}_{2} / \mathrm{kg}$ of lipid (CXS 19-1981, FAO/WHO, 2019).

Maximum acceptable acid value: $0.6 \mathrm{~g} / 100 \mathrm{~g}$ lipid (CXS 19-1981, FAO/WHO, 2019).

Lower and upper limits for vitamin A: 800-1200 g RE/100 g of fresh matter (FM) (CX/NFSDU 19/41/6, FAO/WHO, 2019).

Lower limit for vitamin E: $20 \mathrm{mg}$-TE/100 g of FM (CX/NFSDU 19/41/6, FAO/WHO, 2019).

Different letters correspond to significant differences between samples $(p<0.05)$.

(WHO et al., 2007), but only RUTF 2 complied with the recommendation for vitamin $\mathrm{A}$ (i.e., $0 . \overline{8}-1.2 \mathrm{mg} / 100 \mathrm{~g})(\mathrm{FAO} /$ WHO, 2019). Vitamin A content was low in the other two RUTF types (Fig. 1). The time of storage did not affect vitamin A contents $(p>0.05)$ and variations observed in some samples were likely linked to sample heterogeneity or dosing variability but not to a decrease in vitamin content with time of storage. However, changes in vitamin E content occur after 11 months of storage.

\subsection{Total lipid content and fatty acid profiles}

Lipid content was very variable among the studied RUTFs and ranged from $28.7 \pm 0.5 \mathrm{~g} / 100 \mathrm{~g}$ to $41.2 \pm 2.4 \mathrm{~g} / 100 \mathrm{~g}$ (Tab. 2). Lipid content corresponded to $55.5 \%, 66.8 \%$, and $69.3 \%$ of the total energy for RUTF 1, RUTF 2, and RUTF 3 respectively. As lipids should contribute to $45-60 \%$ of the total
RUTF energy (WHO et al., 2007; FAO/WHO, 2019), two RUTFs exceeded the upper recommended limit.

The main fatty acids were, by decreasing order, C18:1 n-9 (oleic acid), C16:0 (palmitic acid), and C18:2 n-6 (linoleic acid) (Figs. 2 and 3). Their mean percentages in the three RUTF types were $47.2 \pm 7.4 \%, 26.8 \pm 2.1 \%$, and $12.4 \pm 3.9 \%$ of total lipids, respectively (Fig. 2). The time of storage did not influence $(p>0.05)$ the profile of the main fatty acids $\left(\mathrm{C}_{16: 0}, \mathrm{C}_{18: 1{ }_{n-9},}, \mathrm{C}_{18: 2{ }_{n-6}}\right)$. The contents in linoleic acid of the three RUTFs were within the range defined by the international standard (3 to $10 \mathrm{kcal} / 100 \mathrm{kcal}$; FAO/WHO, 2019), with $7.0,4.8$, and $10.2 \mathrm{kcal} / 100 \mathrm{kcal}$ for RUTF 1 , RUTF_2, and RUTF_3 respectively. Their contents in alphalinolenic acid were also in the ranges defined by the international standard $(0.3$ to $2.5 \mathrm{kcal} / 100 \mathrm{kcal}$; FAO/WHO, 2019), with $1.74,0.95$ and $2.41 \mathrm{kcal} / 100 \mathrm{kcal}$ for RUTF 1 , RUTF_2, and RUTF 3 respectively. The mean value of the 


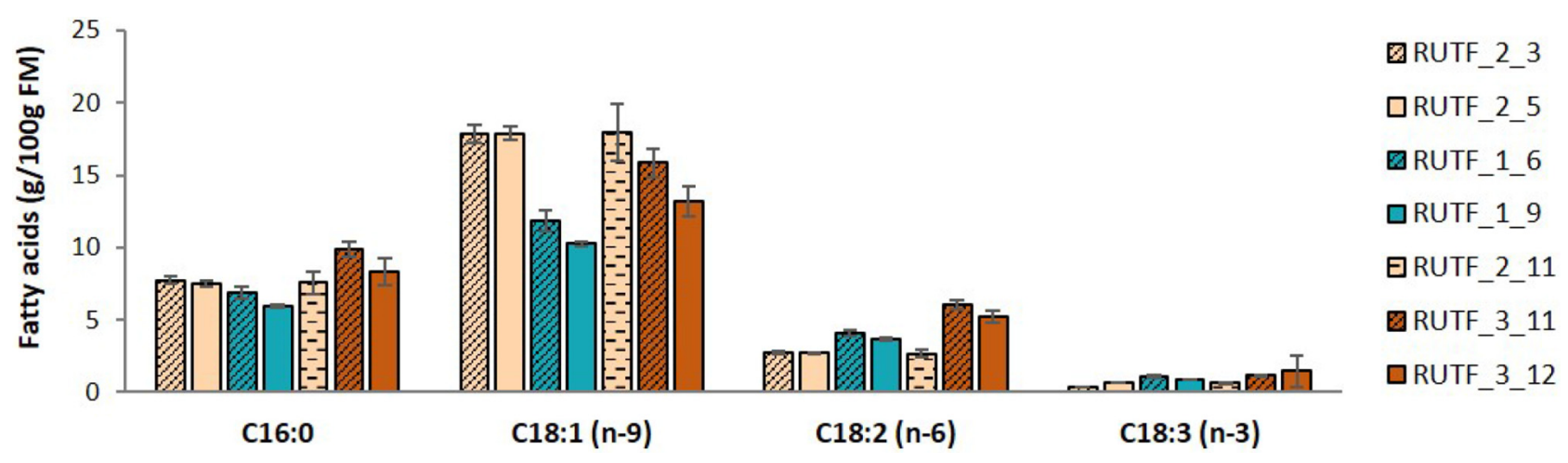

Fig. 2. Main fatty acids in the studied Ready-to-Use Therapeutic Foods (RUTFs). For each fatty acid, the products are classified according to the increasing time of storage, from left to right.

Legend: The products were labeled as follows: RUTF_X_Y to indicate that the RUTF was produced by brand (X) and had been stored for (Y) months at the moment of the analysis.

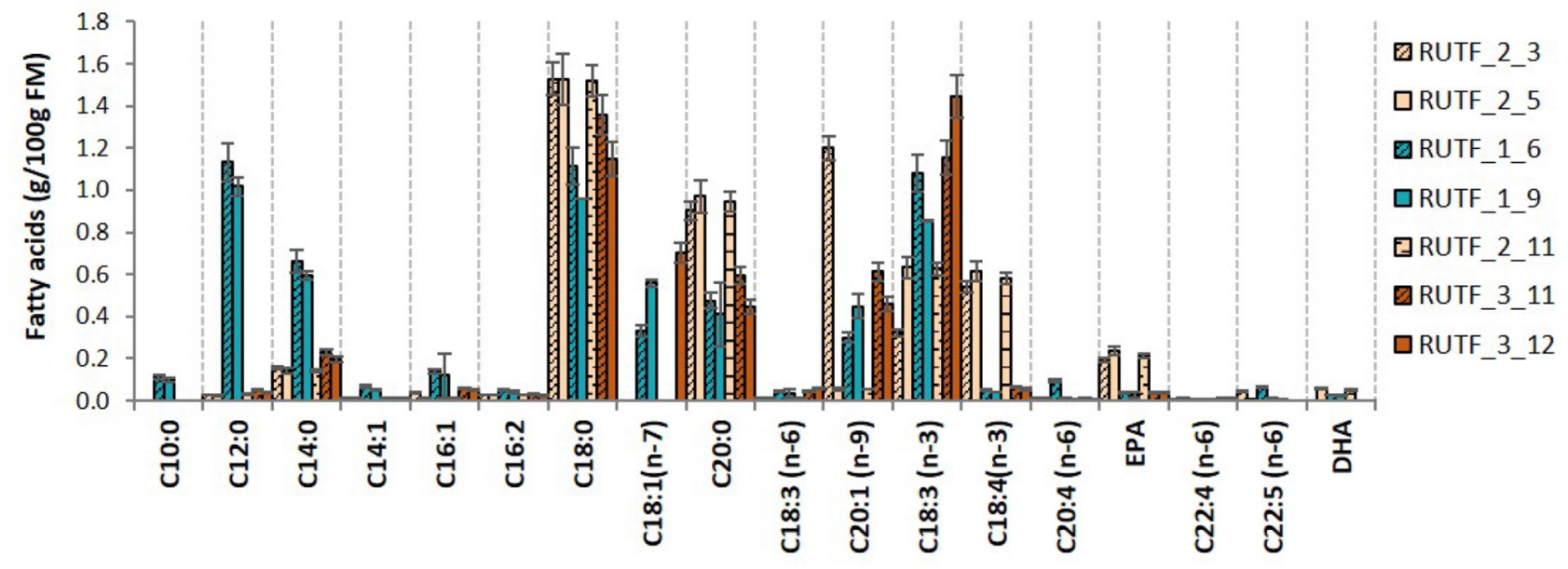

Fig. 3. Fatty acid profile of the studied Ready-to-Use Therapeutic Foods (RUTFs), without C16:0, C18:1(n-9) and C18:2(n-3). The products are classified according to the increasing time of storage, from left to right.

Legend: The products were labeled as follows: RUTF_X_Y to indicate that the RUTF was produced by brand (X) and had been stored for (Y) months at the moment of the analysis.

$\mathrm{n}-6 / \mathrm{n}-3$ ratio in the three products $(3.3 \pm 1.3)$ (Tab. 3 ) was $<4$ (the value recommended for adults), but was rather low compared with the very broad range, between 5 and 15 , recommended for children (Guesnet et al., 2013). RUTF_1 was richer in mediumchain fatty acids (C10:0 and C12:0) than RUTF_2 and RUTF_3 (Fig. 3). TAG represented the main lipid class $(>95 \%$, Tab. $\overline{3})$. The time of storage did not influence the lipid class composition, and almost no TAG, DAG or MAG degradation was observed over time. Only in one product (RUTF_2), TAG was slightly reduced at month 11 after production.

\subsection{Mycotoxin determination}

The maximum aflatoxin content allowed in RUTFs is $5 \mu \mathrm{g} / \mathrm{kg}$ (WHO et al., 2007), but in the future, it may be raised to $10 \mu \mathrm{g} / \mathrm{kg}$ (FAO/WHO, 2019). The RUTF samples did not contain ochratoxins, fumonisins, trichothecenes, zearalenone, and beauvericins. Only RUTF 1 (locally produced in Asia) had an aflatoxin B1 content above the acceptable limit of $5 \mu \mathrm{g} / \mathrm{kg}$ (WHO et al., 2007)

\subsection{Packaging characterization}

The oxygen transmission rate (OTR) represents the quantity of $\mathrm{O}_{2}$ that goes through the packaging per day, and the water vapor transmission rate (WVTR) represents the quantity of $\mathrm{H}_{2} \mathrm{O}$ that diffuses through the packaging per day. Two of the studied RUTF types (RUTF 2, and RUTF 3) were packed in an aluminum/polyethylene multilayer that is a good oxygen and water vapor barrier (Moyssiadi et al., 2004), with OTR and WVTR equal to zero. Polypropylene was used as packaging for RUTF 1, with an OTR of $2.96 \mathrm{~cm}^{3} / \mathrm{cm}^{2}$ and a WVTR of $0.02 \mathrm{~g} / \mathrm{mm}$.

\section{Discussion}

This study compared lipid composition and stability in different RUTFs. Although the three RUTF formulations were different, they were all quite stable over the tested period of 9-12 months. There $a_{w}$ was below 0.6 , indicating a good 
C. Moustiés et al:: OCL 2022, 29, 13

Table 3. Lipid classes and lipid profiles (in percentages) and n-6/n-3 ratios in the studied Ready-to-Use Therapeutic Foods.

\begin{tabular}{|c|c|c|c|c|c|c|c|c|}
\hline & TAG & DAG & MAG & FFA & SFA & MUFA & PUFA & $n-6 / n-3$ \\
\hline RUTF_1_9 & $99.7 \pm 0.1^{\mathrm{ab}}$ & $0.3 \pm 0.1^{\mathrm{ab}}$ & nd & nd & $38.4 \pm 0.5^{\mathrm{c}}$ & $43.2 \pm 0.2^{\mathrm{a}}$ & $18.3 \pm 0.1^{\mathrm{b}}$ & $3.9 \pm 1.3^{\mathrm{c}}$ \\
\hline RUTF_2_5 & $99.8 \pm 0.1^{\mathrm{ab}}$ & $0.2 \pm 0.1^{\mathrm{ab}}$ & nd & nd & $31.4 \pm 0.1^{\mathrm{a}}$ & $55.1 \pm 0.1^{\mathrm{c}}$ & $13.4 \pm 0.2^{\mathrm{a}}$ & $1.8 \pm 0.7^{\mathrm{a}}$ \\
\hline RUTF_2_11 & $95.6 \pm 1.0^{\mathrm{c}}$ & $3.7 \pm 1.0^{\mathrm{c}}$ & $0.3 \pm 0.2$ & $0.4 \pm 0.2^{b}$ & $31.6 \pm 0.2^{\mathrm{a}}$ & $55.2 \pm 0.1^{\mathrm{c}}$ & $13.0 \pm 0.1^{\mathrm{a}}$ & $1.8 \pm 0.3^{\mathrm{a}}$ \\
\hline
\end{tabular}

Data are presented as the mean \pm standard deviation for $100 \mathrm{~g}$ of fresh weight $(n=6)$.

Values with distinct lowercase superscript letters in the same column are significantly different $(p \leq 0.05)$.

TAG: triacylglycerols; DAG: diglycerols; MAG: monoglycerols; FFA: free fatty acids; SFA: saturated fatty acids; MUFA: monounsaturated fatty acids; PUFA: polyunsaturated fatty acids; nd: not detected.

microbial stability (Santini et al., 2013; FAO/WHO, 2016). Moreover, their oxidative stability was adequate, with limited increase in lipid oxidation markers (peroxides, acidity, and secondary oxidative volatile compounds) over the storage period. Similarly, the lipophilic vitamin and mycotoxin contents were not influenced by the storage duration. This good stability is most likely explained by the multilayer packaging for RUTF 2 and RUTF 3.

As RUTF are formulated for children with specific nutritional needs, these products must comply with international nutritional recommendations (WHO et al., 2007; FAO/ WHO, 2019) that are different from those generally used for non-wasted children (FAO, 2010). For example, $100 \mathrm{~g}$ of the three RUTF types provide, on average, $36.7 \pm 12.7 \mathrm{kcal}$ from linoleic acid, and $7.7 \pm 2.8 \mathrm{kcal}$ from $\alpha$-linolenic acid. This could seem high, but their lipid profile was still within the range of the WHO recommendations (2007). Depending on the child's age and weight, the energy intake attributable to linoleic acid and $\alpha$-linolenic acid could be as high as $101.5 \mathrm{kcal}$ and $21.3 \mathrm{kcal}$ respectively, which is four and six times higher than what recommended for non-wasted children (FAO, 2010). Therefore, it is important to note that RUTF should be given only to severely malnourished children in the context of nutritional rehabilitation, and that they may not be beneficial for non-wasted children. Indeed, high $\alpha$-linolenic acid intake associated with high linoleic acid intake could limit DHA biosynthesis by competitive inhibition of PUFA bioconversion. Indeed, it is also important to bear in mind that not only the $n-6 / n-3$ ratio but also the amount of essential FA must be controlled and strategies of supplementation in n-3 to compensate for high n-6 levels are not satisfactory as they depress DHA synthesis as n-3 FA compete with DPA (C22:5n-3) for desaturase (Brenna et al., 2015).

The three-studied RUTF had $n-6 / n-3$ PUFA ratios lower than 5 , although it would be preferable to be closer to 5 (recommended ratio between 5-15) (Guesnet et al., 2013). Usually, infants and children WHO consume RUTF do not receive a diversified diet, and RUTF are probably their only source of essential fatty acids, especially during treatment. As $n-6$ and $n-3$ lipid intake is very high with RUTF, they could have effects on adipogenesis, lipid metabolism and brain development if their consumption is not supervised and if they are taken for extended periods ( $>8$ weeks) (Ailhaud and
Guesnet, 2004; Ailhaud et al., 2006; Massiera et al., 2003). The ratio of $n-6 / n-3$ fatty acids in the brain is between $1: 1$ and $2: 1$, and this should be the target ratio (Simopoulos, 2010). The optimal fatty acid composition of RUTF is still currently under debate but at least two recent random clinical trials have shown beneficial effects on DHA status and development of children receiving a low LA RUTF with added preformed long chain PUFA (EPA and/or DHA) (Stephenson et al., 2021; Jones et al., 2015).

The RUTF under study were rich in monosaturated and saturated fatty acids, with a lower PUFA percentage, which should favor a good lipid stability. One of the specific features of RUTF is their enrichment in medium-chain fatty acids, $\left(\mathrm{C}_{10: 0}\right.$ and $\left.\mathrm{C}_{12: 0}\right)$, a rapid energy source that can be directly metabolized. These medium-chain fatty acids are essential in children with malnutrition (Jensen, 1999; Moltó-Puigmartí et al., 2011). Oleic acid also plays an important role in human metabolism. Indeed, oleic acid is a precursor of eicosatrienoic acid that has an anti-inflammatory role and inhibits the synthesis of inflammatory mediators (Gibson, 2018). The tested RUTF contained mainly lipids in the form of TAG and a minority of DAG, MAG and FFA because the predominant lipid source was plant-based, with TAG predominance. Moreover, in vegetable oil, unsaturated fatty acids, such as linoleic and oleic acid, are favored in the $s n-2$ position (Indelicato et al., 2017), which will not promote their absorption.

Despite their overall stability, two RUTF types had a low content in vitamin A, below the recommended values (WHO et al., 2007; FAO/WHO, 2019). This was possibly due to an inadequate level of vitamin A added to the RUTF during production, or to the degradation of vitamin A during the first months after production, because vitamin A was stable over the study time. However, few data are currently available on vitamin A stability in such complex food systems (Atwood et al., 1995; Loveday and Singh, 2008). For example, in oily products, vitamin $\mathrm{A}$ is added in the chemical form of retinyl palmitate (vitamin A palmitate). However, in other complex food systems (i.e., corn flakes), vitamin A palmitate needs to be protected with a complete vitamin mixture (vitamin $\mathrm{A}, \mathrm{B}_{1}$, $\mathrm{B}_{6}, \mathrm{~B}_{12}, \mathrm{C}$, and $\mathrm{D}$ ) to remain stable (Kim et al., 2000). Moreover, vitamin E plays a role as peroxyl radical scavenger, allowing the maintenance of long-chain PUFA integrity 
(Traber and Atkinson, 2007). Therefore, the studied formulations could be improved by using nano-emulsions, and by optimizing the packaging (multilayer, possibly combined with inert gas injection) to further improve their quality (Manary, 2006; Ozturk, 2017; Santini et al., 2013).

\section{Conclusion}

The studied RUTF were very stable over the tested storage period of 9-12 months. The level of oxidation markers was limited, and their lipid profiles were acceptable. The $n-6 / n-3$ ratio in the three-studied RUTF met the international recommendation but could be higher. The nutritional composition of the most widespread RUTF followed the nutritional recommendations. However, the products conceived in Asia (local production with locally available ingredients) did not comply with the international recommendations for vitamin A content in RUTF (underdosing) and could be further optimized.

\section{Abbreviations}

$\begin{array}{ll}\text { AV } & \text { Acid value } \\ \text { DAG } & \text { Diacylglycerol } \\ \text { DHA } & \text { Docosahexaenoic acid } \\ \text { DM } & \text { Dry matter } \\ \text { HPLC } & \text { High performance liquid chromatography } \\ \text { FFA } & \text { Free fatty acid } \\ \text { FM } & \text { Fresh matter } \\ \text { MAG } & \text { Monoacylglycerol } \\ \text { MCFA } & \text { Medium chain fatty acid } \\ \text { MUAC } & \text { Mid-upper-arm circumference } \\ \text { MUFA } & \text { Monounsaturated fatty acid } \\ \text { PUFA } & \text { Polyunsaturated fatty acid } \\ \text { PV } & \text { Peroxide value } \\ \text { RUTF } & \text { Ready-to-use therapeutic food } \\ \text { SFA } & \text { Saturated fatty acid } \\ \text { TAG } & \text { Triacylglycerol } \\ \text { TLC } & \text { Thin layer chromatography } \\ \text { OTR } & \text { Oxygen transmission rate } \\ \text { UV } & \text { Ultra violet } \\ \text { WHZ } & \text { Weight-for-height Z-score } \\ \text { WVTR } & \text { Water vapor transmission rate }\end{array}$

\section{Conflict of interest}

The authors declare that there is no conflict of interest.

Acknowledgements. This work was supported by the French Ministry of Sciences and Technology (PhD studentship program), UNICEF (Cambodia) and by the French Research on Lipid \& Nutrition (https://lipides-et-nutrition.net/le-gln/).

\section{References}

AACC. 2000. Methods 44-15A, 54-21. In: Approved Methods of the American Association of Cereal Chemists, A.A.O.C. Chemists, Editor. St. Paul, MN.
Ailhaud G, Guesnet P. 2004. Fatty acid composition of fats is an early determinant of childhood obesity: A short review and an opinion. Obes Rev 5: 21-26. https://doi.org/10.1111/ j.1467-789X2004.00121.x.

Ailhaud G, Massiera F, Weill P, Legrand P, Alessandri JM, Guesnet P. 2006. Progress in lipid research temporal changes in dietary fats: Role of $\mathrm{n}-6$ polyunsaturated fatty acids in excessive adipose tissue development and relationship to obesity. Progr Lipid Res 45: 203 236. https://doi.org/10.1016/j.plipres.2006.01.003.

AOCS. 1996. Official methods and recommended practices of the American Oil Chemist's Society, physical and chemical characteristics of oils, fats and waxes, Section I. Ed. The AOCS Methods Editor and the AOCS Technical Department. Champaign: AOCS Press, $54 \mathrm{p}$.

Atwood S, Sanghvi T, Sharma V, Carolan N. 1995. Stability of vitamin $\mathrm{A}$ in fortified vegetable oil and corn soy blend used in child feeding programs in India. J Food Compos Anal 8: 32-44. https://doi.org/0889-1575/95\$6.00.

Berton-Carabin CC, Ropers MH, Genot C. 2014. Lipid oxidation in oil-in-water emulsions: Involvement of the interfacial layer. Compr Rev Food Sci Food Saf 13(5): 945-977. https://doi.org/ 10.1111/1541-4337.12097.

Brenna JT, Akomo P, Bahwere P, et al. 2015. Balancing omega- 6 and omega-3 fatty acids in Ready-to-Use Therapeutic Foods (RUTF). BMC Med 13(1): 1-4. https://doi.org/10.1186/s12916-0150352-1.

Briend A. 2001. Highly nutrient-dense spreads: A new approach to delivering multiple micronutrients to high-risk groups. Br J Nutr 85(2): 175-179. https://doi.org/10.1049/BJN2000311.

Choudhury N, Ahmed T, Hossain MI, et al. 2018. Ready-to-Use Therapeutic Food made from locally available food ingredients is well accepted by children having severe acute malnutrition in Bangladesh. Food Nutr Bull 39(1): 116-126. https://doi.org/ 10.1177/0379572117743929.

Development Initiatives. 2018. 2018 Global Nutrition Report: Shining a light to spur action on nutrition. Bristol, UK: Development Initiatives. Available from https://globalnutritionre port.org/reports/global-nutrition-report-2018/.

Dibari F, Diopel HI, Collins S, Seal A. 2012. Low-cost, Ready-to-Use Therapeutic Foods can be designed using locally available commodities with the aid of linear programming. J Nutr 142(5): 955-61.

Diop EHI, Dossou NI, Ndour MM, Briend A, Wade S. 2003. Comparison of the efficacy of a solid ready-to-use food and a liquid, milk-based diet for the rehabilitation of severely malnourished children: A randomized trial. Am J Clin Nutr 78: 302-307. https://doi.org/10.1093/ajcn/78.2.302.

FAO. 2010. Fats and fatty acids in human nutrition. Report of an Expert Consultation, 10-14 November 2008, FAO Food and Nutrition Paper 91. Geneva, Switzerland. Available from http:// www.fao.org/3/i1953e/i1953e.pdf.

FAO/WHO. 2016. Microbial safety of lipid-based ready-to-use foods for management of moderate acute malnutrition and severe acute malnutrition. Microbiological Risk Assessment Series No. 28. Rome, $66 \mathrm{p}$.

FAO/WHO. 2019. Proposed draft guideline for Ready-to-Use Therapeutic Foods. In: Joint FAO/WHO Food Standards Programme, Codex Committee on Nutrition and Foods for Special Dietary Uses, 41st Session, 24-29 November 2019, Dusseldorf, Germany. Codex Alimentarius Commission, CX/ NFSDU 19/41/6.

FAO/WHO. 2019. Standard for edible fats and oils not covered by individual standards. Codex Alimentarius International food Standards, CXS 19-1981. 
FAO, IFAD, UNICEF, WFP, WHO. 2018. The state of food security and nutrition in the world 2018. Building climate resilience for food security and nutrition. Rome: FAO.

Folch J, Lees M, Sloane Stanley GH. 1957. A simple method for the isolation and purification of total lipids from animal tissues. $\mathrm{J} \mathrm{Biol}$ Chem 226: 497-509.

Gaur S, Sloffer EM, Ojha A, et al. 2017. Omega-3-fortified lipidbased nutrient supplement: Development, characterization, and consumer acceptability. Food Nutr Bull 38(2): 158-171. https:// doi.org/10.1177/0379572117701234.

Gibson RA. 2018. Musings about the role dietary fats after 40 years of fatty acid research. Prostaglandins Leukot Essent Fatty Acids 131: 1-5. https://doi.org/10.1016/j.plefa.2018.01.003.

Guesnet P, Alessandri JM. 2011. Biochimie Docosahexaenoic acid (DHA) and the developing central nervous system (CNS)Implications for dietary recommendations. Biochimie 93(1): 7-12. https://doi.org/10.1016/j.biochi.2010.05.005.

Guesnet P, Delplanque B, Alessandri JM, Bures Y. 2013. Place des lipides dans l'alimentation du nourrisson. OCL 20(2): 79-87. https://doi.org/10.1684/ocl.2013.0499.

Headey D, Heidkamp R, Osendarp S, et al. 2020. Impacts of COVID-19 on childhood malnutrition and nutrition-related mortality. Lancet 396: 519-521. https://doi.org/10.1016/S0140-6736(20)31647-0.

Hsieh JC, Zeilani M, Ickes S, et al. 2016. High oleic Ready-to-Use Therapeutic Food maintains docosahexaenoic acid status in severe malnutrition: A randomized, blinded trial. J Pediatr Gastroenterol Nutr 61(1): 138-143. https://doi.org/10.1097/ MPG.0000000000000741.High.

Indelicato S, Bongiorno D, Pitonzo R, et al. 2017. Triacylglycerols in edible oils: Determination, characterization, quantitation, chemometric approach and evaluation of adulterations. J Chromatogr A 1515: 1-16. https://doi.org/10.1016/j.chroma.2017.08.002.

Jensen RG. 1999. Lipids in human milk. Lipids 34(1): 1243-1271. https://doi.org/10.1016/j.beem.2017.11.002.

Jones KDJ, Ali R, Khasira MA, et al. 2015. Ready-to-Use Therapeutic Food with elevated n-3 polyunsaturated fatty acid content, with or without fish oil, to treat severe acute malnutrition: A randomized controlled trial. BMC Med 13: 1-14. https://doi. org/10.1186/s12916-015-0315-6.

Kapil U. 2009. Ready-to-Use Therapeutic Food (RUTF) in the management of severe acute malnutrition in India. Indian Pediatr 46(5): 381-382. http://www.ncbi.nlm.nih.gov/pubmed/ 19478351.

Khara T, Collins S, International V. 2004. Community-based Therapeutic Care (CTC) (Special Supplement Series No. 1). Oxford.

Kim YS, Dickmann R, Warthesen J. 2000. Degradation of Vitamin A palmitate in corn flakes during storage. J Food Sci 65(7): 1216-1219. https://doi.org/10.1111/j.1365-2621.2000. tb10268.x.

Kritchevsky D. 2002. Fats and oils in human health. In: Food lipids. New York: Marcel Dekker Inc., pp. 449-462.

Lebrun M, Plotto A, Goodner K, Ducamp M, Baldwin E. 2008. Discrimination of mango fruit maturity by volatiles using the electronic nose and gas chromatography. Postharvest Biol Technol 48: 122-131. https://doi.org/10.1016/j.postharv bio.2007.09.010.

Loveday SM, Singh H. 2008. Recent advances in technologies for vitamin A protection in foods. Trends Food Sci Technol 19(12): 657-668. https://doi.org/10.1016/j.tifs.2008.08.002.

Manary MJ. 2006. Local production and provision of Ready-to-Use Therapeutic Food (RUTF) spread for the treatment of severe childhood malnutrition. Food Nutr Bull 27(3): 83-89. https://doi. org/10.1177/15648265060273S305.
Massey LK. 2003. Permeability properties of plastics and elastomers. In: W. Andrew, ed. A guide to packaging and barrier materials, 2nd ed.

Massiera F, Saint-Marc P, Seydoux J, et al. 2003. Arachidonic acid and prostacyclin signaling promote adipose tissue development: A human health concern? J Lipid Res 44: 271-279. https://doi. org/10.1194/jlr.M200346-JLR200.

Mc Clements DJ. 2000. Lipid oxidation in oil-in-water emulsions: Impact of molecular environment on chemical. J Food Sci 65(8): 1270-1282. https://doi.org/10.1016/j.foodchem.2011.09.032.

Moltó-Puigmartí C, Isabel A, Carbonell-Estrany X, López-Sabater MC. 2011. Differences in fat content and fatty acid proportions among colostrum, transitional, and mature milk from women delivering very preterm, preterm, and term infants. Clin Nutr 30: 116-123. https://doi.org/10.1016/j.clnu.2010.07.013.

Moustiés C, Bourlieu-Lacanal C, Barea B, et al. 2019. Lipid composition and state of oxidation of fortified infant flours in lowincome countries are not optimal and strongly affected by the time of storage. Eur J Lipid Sci Technol 121(11): 1900173. https://doi. org/10.1002/ejlt.201900173.

Moyssiadi T, Badeka A, Kondyli E, Vakirtzi T, Savvaidis I, Kontominas MG. 2004. Effect of light transmittance and oxygen permeability of various packaging materials on keeping quality of low fat pasteurized milk: Chemical and sensorial aspects. Int Dairy J 14(5): 429-436. https://doi.org/10.1016/j. idairyj.2003.09.001.

Mridha M, Chaparro C, Matias S, et al. 2012. Acceptability of lipidbased nutrient supplements and micronutrient powders among pregnant and lactating women and infants and young children in Bangladesh and their perceptions about malnutrition and nutrient supplements. Washington, DC: FHI 360/ FANTA-2 Bridge.

Nestel P, Briend A, De Benoist B, et al. 2003. Complementary food supplements to achieve micronutrient adequacy for infants and young children. J Pediatr Gastroenterol Nutr: 316-328. https:// doi.org/10.1097/00005176-200303000-00005.

Nga TT, Nguyen M, Mathisen R, et al. 2013. Acceptability and impact on anthropometry of a locally developed Ready-to-Use Therapeutic Food in pre-school children in Vietnam. Nutr $J$ 12: 1-8. https://doi.org/10.1186/1475-2891-12-120.

Olagunju O, Mchunu N, Durand N, Alter P, Montet D, Ijabadeniyi O. 2018. Effect of milling, fermentation or roasting on water activity, fungal growth, and aflatoxin contamination of Bambara groundnut (Vigna subterranea (L.) Verdc). LWT-Food Sci Technol 98: 533-539. https://doi.org/10.1016/j.lwt.2018.09.001.

Owino VO, Irena AH, Dibari F, Collins S. 2014. Original article development and acceptability of a novel milk-free soybeanmaize-sorghum Ready-to-Use Therapeutic Food (SMS-RUTF) based on industrial extrusion cooking process. Matern Child Nutr 10: 126-134. https://doi.org/10.1111/j.1740-8709.2012.00400.x.

Ozturk B. 2017. Nanoemulsions for food fortification with lipophilic vitamins: Production challenges, stability, and bioavailability: Nanoemulsion delivery systems for lipophilic vitamins Review Article Nanoemulsions for food forti fi cation with lipophilic vitamins. Eur J Lipis Sci Technol 118: 2010-2011. https://doi.org/ 10.1002/ejlt.201500539.

Riveros CG, Mestrallet MG, Gayol MF, Quiroga PR, Nepote V, Grosso NR. 2010. Effect of storage on chemical and sensory profiles of peanut pastes prepared with high-oleic and normal peanuts. $J \mathrm{Sci}$ Food Agric: 2694-2699. https://doi.org/10.1002/jsfa.4142.

Santini A, Novellino E, Armini V, Ritieni A. 2013. State of the art of Ready-to-Use Therapeutic Food: A tool for nutraceuticals addition to foodstuff. Food Chem 140: 843-849. https://doi. org/10.1016/j.foodchem.2012.10.098. 
Shils ME, Shike M. 2006. Modern nutrition in health and disease, 10th ed.. Philadelphia: Lippincott Williams \& Wilkins.

Sigh S, Roos N, Sok D, Dijkhuizen MA, Wieringa FT. 2018. Development and acceptability of locally made fish-based, readyto-use products for the prevention and treatment of malnutrition in Cambodia. Food Nutr Bull: 1-15. https://doi.org/10.1177/ 0379572118788266.

Simopoulos AP. 2010. The omega-6/omega-3 fatty acid ratio: Health implications. OCL 17(5): 267-275. https://doi.org/10.1684/ ocl.2010.0325.

Stephenson K, Callaghan-Gillespie M, Maleta K, et al. 2021. Low linoleic acid foods with added DHA given to Malawian children with severe acute malnutrition improve cognition: A randomized, triple blinded, controlled clinical trial. Am J Clin Nutr, nqab363. https://doi.org/10.1093/ajcn/nqab363.

Thapa BR, Goyal P, Menon J, Sharma A. 2017. Acceptability and efficacy of locally produced Ready-to-Use Therapeutic Food nutreal in the management of severe acute malnutrition in comparison with defined food. Food Nutr Bull 38(1): 18-26. https://doi.org/10.1177/0379572116689743.
Traber MG, Atkinson J. 2007. Vitamin E, antioxidant and nothing more. Free Radical Biol Med 43(1): 4-15. https://doi.org/ 10.1016/j.freeradbiomed.2007.03.024.

Weber J, Callaghan M. 2016. Optimizing Ready-to-Use Therapeutic Foods for protein quality, cost, and acceptability. Food Nutr Bull 37(Supplement 1): 37-46. https://doi.org/10.1177/ 0379572116629257.

WHO. 2013. Guideline: Updates on the management of severe acute malnutrition in infants and children. Geneva: World Health Organization.

WHO, World Food Programme, U.N. System Standing Committee on Nutrition, and UNICEF. 2007. Community-based management of severe acute malnutrition: A Joint Statement by the WHO, World Food Programme, U.N. System Standing Committee on Nutrition and UNICEF. New York: WHO/ UNICEF.

Wieringa FT, Hoang M, Brown M, Maalouf-Manasseh Z, Berger J. 2013. Acceptability of two Ready-to-Use Therapeutic Foods among HIV-positive patients in Vietnam. Washington.

Cite this article as: Moustiés C, Bourlieu-Lacanal C, Hemery YM, Baréa B, Villeneuve P, Servent A, Alter P, Lebrun M, Laillou A, Wieringa FT, Avallone S. 2022. Nutritional quality of Ready-to-Use Therapeutic Foods: focus on lipid composition and vitamin content. OCL 29: 13 . 